I Instituto Piaget, Research in Education and Community Intervention (RECI);

Universidade do Porto, Instituto de Sociologia, Portugal

maria.joao.oliveira@hotmail.com

Maria João Oliveira'

\title{
INSCRIÇÕES NO ESPAÇO SOCIAL: OS IMIGRANTES BRASILEIROS NO GRANDE PORTO
}

Conhecido pela sua longa tradição de emigração, Portugal começa simultaneamente a receber imigrantes de uma forma mais intensificada a partir da segunda metade da década de I970, contabilizando, em 20I4, aproximadamente 859 mil pessoas nascidas no exterior e com residência habitual no país, o que representa $8,2 \%$ da população total (Eurostat, 20I4).

Resultado do crescimento expressivo desses fluxos, bem como do aumento significativo da sua diversidade, a paisagem sociocultural tem sofrido inúmeras mudanças e, por consequência, têm-se problematizado muitas e novas questões - desde logo, em torno do papel do Estado enquanto instituição capaz de receber e lidar com a fixação dos imigrantes. Além disso, determinados grupos ou instituições podem assumir um papel de mediação entre os migrantes e as instituições políticas ou econômicas. Por fim, os recursos que os imigrantes são capazes de mobilizar, especialmente por meio das redes sociais informais desenvolvidas por eles mesmos, desempenham também um papel na forma como eles lidam com a migração e o assentamento.

Nesta pesquisa, toma-se o fluxo de imigrantes brasileiros para compreender algumas dessas novas questões mas, também, aprofundar velhas problemáticas, estimuladas por um contingente populacional que, não tendo parado de crescer desde a década de I980, se intensificou grandemente na primeira década do século XXI e representa a principal população estrangeira residente em Portugal. Tivemos como objetivo principal compreender a forma 
como um deslocamento intersistemas de ordem e de interação (migrações) (Pires, 2003a) se relaciona com as inscrições dos imigrantes brasileiros no espaço social. Para tanto, procedemos à análise das dimensões social, política e cultural do fenômeno, entendidas em sua articulação e influência mútua.

Elegeu-se o Grande Portor como área geográfica de interesse por ter sido a primeira e principal região de envio de emigrantes portugueses para o Brasil (Alves, I994) - contribuindo largamente para o fortalecimento dos laços criados entre os dois países -, mas também por ser frequentemente esquecida pelas pesquisas mais recentes, pese o fato de os fluxos de imigrantes brasileiros para essa região do país se terem igualmente intensificado.

\section{A INTEGRAÇÃO DOS IMIGRANTES NA SOCIEDADE DE ACOLHIMENTO}

Balizados pela perspectiva construtivista, que segue de perto o construtivismo estruturalista de Pierre Bourdieu - e que portanto obriga a uma análise simultaneamente macro e microssociológica e a uma definição relacional do social, concretizada na relação entre o habitus e o campo -, mobilizamos, no âmbito da sociologia das migrações, a teoria dos sistemas migratórios ( $\mathrm{Ma}$ bogunje, I970; Kritz, Lim \& Zlotnik, I992). Recuperamos tal teoria não pelo seu caráter explicativo em relação aos movimentos migratórios, mas pelo seu potencial analítico que decorre de analisar as migrações como o resultado da interação de estruturas macro, meso e micro, sem que existam claras linhas de divisão entre elas. E também por se mostrar útil à análise dos movimentos migratórios como aqueles que existem entre Portugal e o Brasil (Góis \& Marques, 2009), posto que surgem a partir de relações prévias entre países emissores e receptores com base em colonização, influência política, comércio, investimento e laços culturais.

Subjacente ao estudo das migrações está, portanto, a problemática dos processos de incorporação dos imigrantes às sociedades de acolhimento. Referimo-nos ao processo de integração de forma lata, que envolve integração social (das relações sociais etnicamente diversificadas), mas também estrutural (emprego, estada, participação social e política etc.) e cultural (aculturação, mudança cultural e cognitiva). Modos de integração que não devem ser confundidos, ainda, com o processo de identificação dos imigrantes e que remetem ao nível subjetivo do sentimento de pertença nacional e/ou étnico (Heckmann, 2005: 100).

O que aqui nos interessa não é, pois, a integração enquanto fim, mas, antes, seu estudo como processo, cujo resultado se constata, mas que não se pode compreender de modo acabado porque envolve todo o ser social das pessoas implicadas e a sociedade no seu conjunto (Sayad, I999: 305). Uma problemática tão mais decisiva na esfera das migrações devido ao caráter frequentemente disruptivo a ela associado: apresentam-se como "situações críticas não só sobre a ordem interativa, mas também sobre o próprio habitus, 
disrupções estas que constituem potenciais momentos de aprendizagem social, eventualmente incorporável sob a forma de um novo estrato de disposições generativas" (Pires, 2003a: 50).

Nessa linha, o termo integração remete a "uma pluralidade vasta, aberta e mutável de estilos de vida, todos partilhando a cidadania" (Almeida, I993: 830-83I). O essencial é, segundo o autor, não a homogeneização, mas o aprofundamento e expressão das capacidades de escolha, pelo que se entende que a integração não se deve confundir com uma simples forma de promoção social. No entanto, concordamos com o autor quando insiste em afirmar que, por mais relevantes que se considerem ser outros aspectos da exclusão, a pobreza ocupa o lugar mais importante, até pelos efeitos negativos de contágio que tende a produzir sobre todos os outros recursos.

Em estreita articulação com esses pressupostos, adota-se nesta pesquisa a perspectiva de Machado (2002), para quem a redução dos contrastes sociais das minorias é indispensável para se poder falar em integração, não sendo o mesmo necessário em relação aos contrastes culturais, posto que diversidade e integração são compatíveis. Para o eixo social da etnicidade concorrem, fundamentalmente, a dimensão da composição de classe, mas também a sociodemográfica e residencial. Por seu lado, no eixo cultural, a dimensão de maior relevância é a orientação das sociabilidades, embora a língua e a religião também importem. Ao observar como os dois eixos se cruzam, podemos encontrar situações de etnicidade forte, quando ocorrem contrastes relevantes nos níveis social e cultural e, no outro extremo, situações de não etnicidade, quando as continuidades sociais e culturais assumem expressão máxima.

Tal como Machado (2002), não concebemos a integração como um processo fechado, mas antes numa linha de contrastes e continuidades, tanto sociais como culturais, destacando que situações de desigualdade social extremas representam exclusão e, por conseguinte, ausência de integração. Nesse sentido, como Vala (I996: 28) salienta, as pertenças deixam de ser "uma questão de tudo ou nada para passar a ser uma questão de grau".

\section{Modelo analítico}

Os processos de integração dependem, em primeiro lugar, das caraterísticas da população imigrada (Pires, 2003a: I05-I07), nomeadamente, do próprio funcionamento da rede migratória, dos projetos iniciais de migração e das competências, dos recursos e oportunidades que esses indivíduos podem mobilizar, geralmente deficitários (Vilaça, 2008: 83). Remetem à problemática das classes e do volume e estrutura dos capitais, em que o capital econômico tem papel primordial (Bourdieu, 2010). Uma análise tão mais pertinente por estarmos tratando de uma imigração com motivações predominantemente econômicas e profissionais (Malheiros, 2007: 34). 
Em segundo lugar, a integração depende das orientações das políticas dos Estados nacionais, principalmente na regulação das entradas, pelo que, quanto maior for sua restrição, maior será a tendência a cair nas redes da informalidade e ilegalidade, o que leva a um reforço potencial das dinâmicas intramigrantes e da etnicidade. Por outro lado, quanto mais restritivo for o acesso à nacionalidade, mais o acesso aos direitos ficará limitado, e o "imigrante tende a ser definido e a autodefinir-se como estranho, e maior é portanto a probabilidade de emergência de uma etnicidade reativa" (Pires, 2003a: 106).

Em terceiro lugar, os processos de integração dependem da dimensão cultural, o que remete às redes de sociabilidade primárias (redes familiares, de amizade, família e vizinhança) e secundárias e, portanto, à noção de capital social (Bourdieu, I980), externo ou interno (Machado \& Abranches, 2007), e de capital social negativo (Portes, 200o). Outros vetores de análise cultural remetem aos contrastes e continuidades no nível da língua, dos valores, costumes e crenças (Machado, 2002); da confiança nas instituições da sociedade de acolhimento (Vilaça, 2008); e das reações sociais à imigração, como discriminação e estigmatização, em que "a cor da pele ou outro qualquer atributo são tão só os critérios simbólicos usados para delimitar as fronteiras raciais ou étnicas" (Pires, 2003a: 107).

\section{Procedimentos técnico-metodológicos}

Testou-se a teoria por meio de uma estratégia de tipo misto (Creswell, 1994) que articulou as metodologias quantitativa/extensiva, dominante na pesquisa, e qualitativa/intensiva. ${ }^{2}$ Concretamente, devido às caraterísticas da população brasileira - dispersa no território das cidades portuguesas e sem agregação nítida em áreas residenciais (Bógus, 2007: 53) - recorreu-se a amostragem por áreas (Ferreira, 2003) definidas a priori mediante critérios teóricos e informações gerais recolhidas, com o objetivo de captar a maior diversidade possível de inquiridos no que diz respeito a dois tipos de critérios: de gênero e de idade. Trata-se de pequenos locais de concentração ${ }^{3}$ nos três municípios mais representativos da população brasileira no Grande Porto Matosinhos, Porto e Vila Nova de Gaia -, locais que constituem as unidades de observação nas quais se aplicou a técnica do inquérito por questionário. ${ }^{4}$ Utilizou-se a análise de correspondências múltiplas (ACM) para os dados assim obtidos com a finalidade de verificar os eixos estruturantes do espaço social da sociedade de acolhimento. 


\section{INSCRIÇÕES NO ESPAÇO SOCIAL: RESULTADOS}

Da estratégia seguida resultou uma amostra com algumas caraterísticas não muito diferentes daquelas relativas aos dados conhecidos em nível nacional. Trata-se de um contingente populacional majoritariamente feminino e em idade ativa, com forte concentração entre os I8 e os 39 anos, e particularmente distribuído nos níveis secundário e superior de ensino.

\begin{tabular}{l|l|l|l}
\hline & Masculino & Feminino & Total \\
\hline I8-29 anos & $\mathrm{I} 3,7$ & $\mathrm{I9,2}$ & 32,9 \\
\hline 30-39 anos & $\mathrm{I} 9,9$ & 20,5 & 40,4 \\
\hline $40-49$ anos & 7,5 & $\mathrm{I} 3$ & 20,5 \\
\hline 50 e anos & 2,7 & 3,4 & 6,2 \\
\hline $\begin{array}{l}\text { Até ensino básico/fundamental } \\
\text { Ensino secundário/ensino médio completo } \\
\text { ou incompleto }\end{array}$ & 7,5 & 8,9 & $\mathrm{I} 6,4$ \\
\hline Ensino superior completo ou incompleto & 24 & $\mathrm{I} 7,8$ & $4 \mathrm{I}, 8$ \\
\hline
\end{tabular}

Tabela:

Percentual dos inquiridos por gênero, faixa etária e escolaridade

Profissionalmente, é uma população predominantemente ativa, particularmente trabalhadores dos serviços e vendedores $(42,2 \%)$, mas também trabalhadores das profissões intelectuais e científicas $(20,7 \%)$, das profissões de nível intermédio (13,3\%) e, ainda, trabalhadores não qualificados (1 2,6\%). Por relação, estão sobretudo ligados aos lugares de classe ${ }^{5}$ da pequena burguesia de execução (5I,4\%), mas também da pequena burguesia intelectual e científica (15,8\%) e burguesia profissional (10,3\%).

Relativamente à fixação no território, são residentes de 35 freguesias $^{6}$ do Grande Porto, sobretudo dos municípios do Porto (34\%), Matosinhos (25,7\%) e Vila Nova de Gaia (20,8\%), em zonas residenciais onde moram só portugueses $(54,9 \%)$ ou majoritariamente portugueses, mas também alguns brasileiros $(40,3 \%)$.

São majoritariamente imigrantes da chamada segunda onda $(93, \mathrm{I} \%)$ de imigração brasileira para Portugal - isto é, imigrantes que entraram em Portugal a partir da segunda metade da década de I990 - e que emigraram diretamente do Brasil para Portugal (94,5\%) essencialmente à procura de trabalho ou melhores condições de vida (44,I\%), para se juntar à família $(25,5 \%)$ ou para estudar (I6,6\%). Indivíduos que entraram, também na sua maioria, em território nacional com documentação válida para fins turísticos (6I\%), apesar dos projetos de vida de médio e longo prazos. 


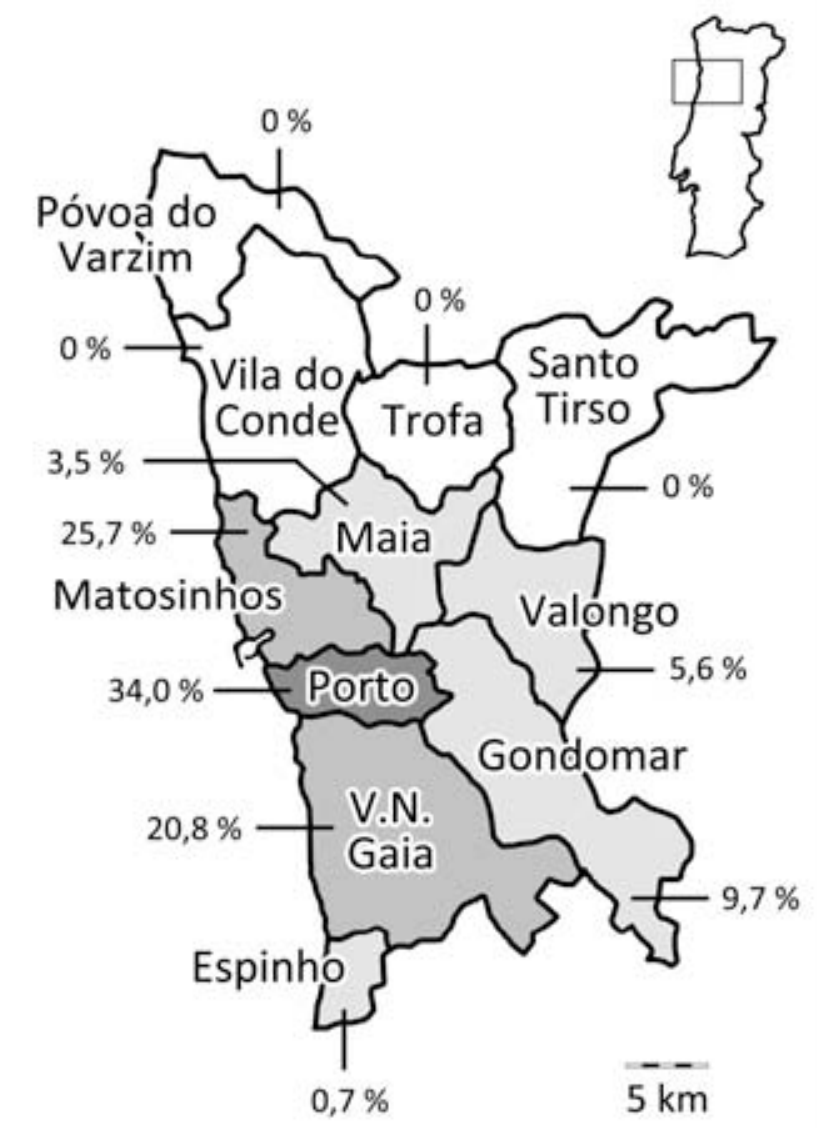

\section{Mapa I:}

Área de residência dos respondentes, por município Fonte:

Projeto coordenado pelo autor.

\subsection{Configuração topológica da dimensão social}

Subjacente à teoria das classes sociais está a ideia de que a sociedade é internamente diferenciada e os indivíduos se agregam em função de semelhanças sociais, o que Weber (I983) chamou de "afinidades eletivas" e Nunes \& Miranda (I969) de "interação preferencial". Diferenças que se definem a partir de lugares ocupados na divisão social do trabalho, mas que não se reduzem à esfera econômica, evidenciando-se, portanto, em outros níveis. Com efeito, a análise do espaço social implica a abordagem dos lugares de classe opera- 
cionalizados a partir de indicadores socioprofissionais e socioeducacionais que são centrais "na estruturação das relações sociais contemporâneas e na distribuição diferencial de recursos e poderes, disposições e oportunidades de indivíduos, famílias e grupos" (Costa, I999: 224).

Portanto, os indivíduos não se movem ao acaso no espaço social, nem a posição e a trajetória individual são estatisticamente independentes ou as posições de chegada são igualmente prováveis para todos os pontos de partida (Bourdieu, 20I0: I89). No entanto, porque consideramos os problemas metodológicos levantados pela mobilidade social no espaço geográfico internacional (Machado, 2002: 209), avançamos para uma análise que privilegia as continuidades e descontinuidades de classe em detrimento da ideia de mobilidade ascendente/descendente aplicada a esses trajetos.

\section{Configuração topológica do espaço social da sociedade de origem}

Para compreender como está organizado o espaço social, por meio de uma ACM colocaram-se em análise as diferentes variáveis da dimensão social (sociodemográficas, de condição profissional e de classe), no sentido de apreender a importância das relações que se estabelecem entre elas.?

Como estamos tratando de um processo que envolve dois momentos e dois espaços - o da sociedade de origem e o da sociedade de acolhimento -, mas que não são independentes, começaremos por analisar como se caracteriza o espaço social de partida para depois melhor compreender a forma como a mudança entre sistemas de ordem e de interação (migração) potencializa ou não uma reorganização da importância das relações que se estabelecem entre as variáveis. Além das variáveis sociodemográficas, profissionais e de classe, introduzimos a variável razão de emigrar, que nos ajuda a contextualizar as condicionantes de partida.

Na sociedade de origem (Gráfico I), à exceção das variáveis gênero e situação na profissão, os demais indicadores apresentam medidas de discriminação bem mais elevadas (pelo menos em uma das duas primeiras dimensões) e, portanto, diferenciam os objetos em análise. Conclui-se, portanto, que ser mulher ou homem, patrão, trabalhador por conta própria ou assalariado, no que se refere à identificação dos lugares ocupados nesse espaço social, parece ser relativamente indiferente.

No que diz respeito às variáveis retidas pela análise, a dimensão I se distingue por associar as variáveis idade e condição perante o trabalho, dividindo ainda com a dimensão 2 as variáveis relativas ao lugar de classe individual e a razão de emigrar para Portugal. Privilegiando as categorias que são importantes e, de preferência, simultaneamente bem representadas na dimensão, nos damos conta de que a dimensão I discrimina essencialmente em função do ciclo de vida I (alfa = 0,786; variância explicada =7,II\%). Assim, no lado esquerdo do quadrante, associam-se os indivíduos que emigraram entre 
os 30 e os 39 anos, que exerciam alguma profissão em tempo integral, que pertenciam ao operariado industrial (OI) e que migraram por razões de trabalho. Por oposição, no lado direito do quadrante, associam-se os indivíduos que emigraram com idade igual ou inferior a I8 anos, que eram estudantes, que migraram para se juntar à família e que pertenciam à pequena burguesia proprietária e assalariada (PBPA) - precisamente uma fração de classe composta, que diz respeito aos casos que, em decorrência de nunca terem trabalhado, foram identificados em função do lugar de classe de família.

Na dimensão 2, além das variáveis lugar de classe individual e razão de emigrar para Portugal, estão os recursos escolares e a pertença a um grupo profissional (alfa $=0,78 \mathrm{I}$; variância explicada $=7 \%$ ). Concretamente, opõem-se os indivíduos com ensino superior, especialistas das atividades intelectuais e científicas (grupo 2), pertencentes à pequena burguesia intelectual e científica (PBIC) e que também migraram para estudar, aos que possuem nível de formação fundamental ou médio, ligados ao trabalho qualificado da indústria, construção e artífices (grupo 7), com pertença ao OI e que migraram em razão de trabalho. Isso nos permite concluir que há claramente, pelo menos, dois perfis distintos no que diz respeito ao brasileiro que emigrou para Portugal e que atualmente reside no Grande Porto. Indivíduos que se distinguem pelo ciclo de vida em que se encontravam, pelos níveis de qualificação escolar e profissional que possuíam e que, em razão dessas duas condições, buscam objetivos diferentes com o projeto migratório (Gráfico I, p. 467).

\section{Configuração topológica do espaço social da sociedade de acolhimento}

Com relação à sociedade de acolhimento (Gráfico 2), a variável gênero permanece como não discriminante do espaço social, mas se acresce da variável idade. No entanto, outras variáveis marcam com alguma importância esse espaço. Particularmente, na dimensão I são discriminantes as variáveis relativas aos recursos escolares, de condição perante o trabalho, grupo profissional e lugar de classe individual, enquanto a dimensão 2 é claramente marcada pelo estado civil e situação na profissão, mas também, embora menos discriminante, pela origem do cônjuge.

Nos quadrantes da primeira dimensão (alfa = 0,794; variância explica$\mathrm{da}=9,03 \%$ ), do lado direito, associam-se os indivíduos com escolaridade secundária/média, que em Portugal não procuraram melhorar sua formação ou ter oficialmente reconhecido seu nível de escolaridade, que trabalham nos serviços pessoais, de proteção e segurança e como vendedores (grupo 5) ou em trabalhos não qualificados (grupo 9) e que pertencem à pequena burguesia de execução (PBE). Por oposição, no quadrante à esquerda, encontram-se os estudantes e trabalhadores-estudantes, indivíduos que frequentam ou possuem ensino superior, obtido no Brasil e reconhecido ou aprimorado em Portugal, que têm ligação com as profissões intelectuais e científicas (grupo 


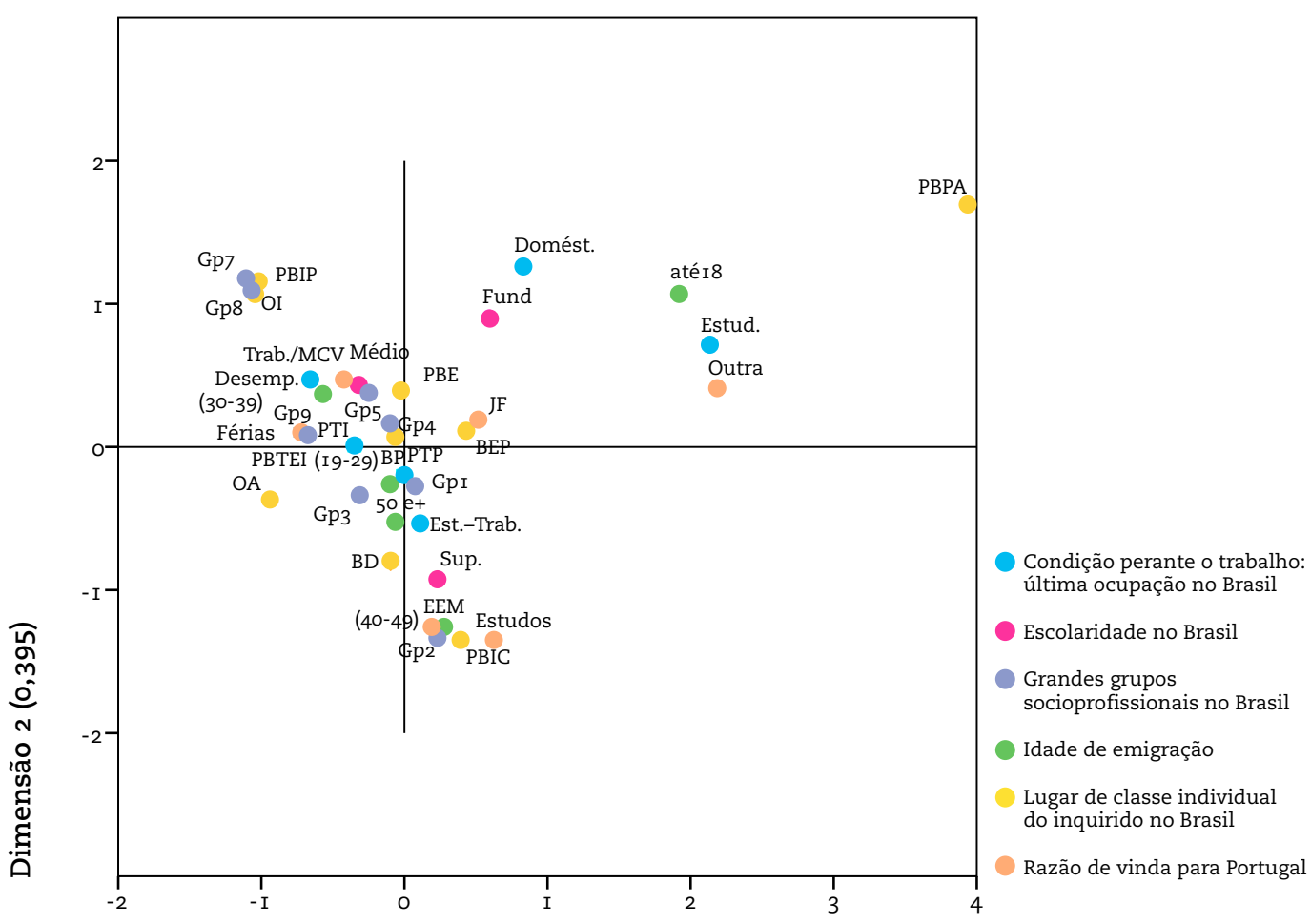

\section{Dimensão I (o,40I)}

\section{Gráfico I:}

Configuração topológica do espaço social da sociedade de origem

Fonte:

Projeto coordenado pelo autor.

\section{Condição perante o trabalho:}

Profissão em tempo integral (PTI); Profissão em tempo parcial (PTP);

Estudante (Estud.); Estudante-trabalhador (Est.-Trab.); Doméstico (Domést.);

Desempregado (Desemp.); Formação profissional (FP).

Nível de escolaridade no Brasil:

Ensino fundamental (Fund.); Ensino médio/profissionalizante (Médio);

Ensino superior (Sup.).

Razão de vinda para Portugal:

Trabalho/melhores condições de vida (Trab/MCV); Estudos;

Para se juntar à família (JF); Férias; Estágio, especialização profissional, missões de serviço (EEM); Outra.

Nota:

As não respostas, porque residuais, não foram incluídas na análise. 
2) e que pertencem à PBIC ou à burguesia profissional (BP). Ou seja, se no Brasil eram categorias discriminantes, em lados opostos, a PBIC e o OI, em Portugal passamos a ter a PBIC e a PB por oposição à PBE. Na mesma linha, se em qualquer uma das sociedades exercer alguma atividade intelectual e científica constitui profissão discriminante, já no que concerne aos trabalhadores qualificados da indústria, estes são substituídos na sua importância pelo pessoal dos serviços e os trabalhadores não qualificados.

Na segunda dimensão (alfa = 0,703; variância explicada $=7,02 \%$ ), acima do quadrante estão os solteiros e abaixo estão os casados ou que vivem em união de fato. Já a variável origem do cônjuge (por si só menos discriminante na dimensão) não acrescenta informação porque, na verdade, tem como únicas categorias discriminantes, no mesmo lado do plano, os casados com cônjuge brasileira e portuguesa. Ou seja, a origem étnica do cônjuge não se confirma como indicador discriminante. O que discrimina é o estado civil, sendo que aos casados se juntam, no mesmo lado do plano, os patrões com mais de quatro funcionários, os dirigentes, diretores e gestores executivos (grupo I) e os que pertencem à burguesia empresarial e proprietária (BEP). Por seu lado, aos solteiros juntam-se os assalariados, particularmente, trabalhadores em tempo parcial, os que exercem profissões intelectuais e cientistas (grupo 2) e que pertencem à PBIC (Gráfico 2, p. 469).

\subsection{Configuração topológica da dimensão política}

Devido ao fato de os imigrantes serem largamente classificados como trabalhadores temporários, a migração internacional é com frequência considerada fenômeno socioeconômico em grande parte desprovido de significado político. No entanto, autores como Castles e Miller (2003) defendem que, mais do que a forma como os processos migratórios funcionam, são precisamente as políticas nacionais sobre a imigração em assuntos como a permanência, o acesso à cidadania e o pluralismo cultural que distinguem os Estados. Por essa razão, continuam os autores - e levando em consideração o fato de que as políticas de imigração têm consequências muito concretas, entre outros aspectos, na relação que o imigrante estabelece com o mercado de trabalho, na sua participação política e no acesso à naturalização -, as políticas que ignoram a realidade da imigração, sobretudo aquelas que tendem a perpetuar a imagem do imigrante como temporário, conduzem à marginalização social, à formação de minorias e à discriminação.

Assim, nesta pesquisa interessou-nos compreender a forma como a condição legal dos imigrantes e o tempo de permanência na sociedade de acolhimento se relacionam com outras caraterísticas, especificamente, sociodemográficas, participação nos grupos profissionais e de classe (Gráfico 3). 


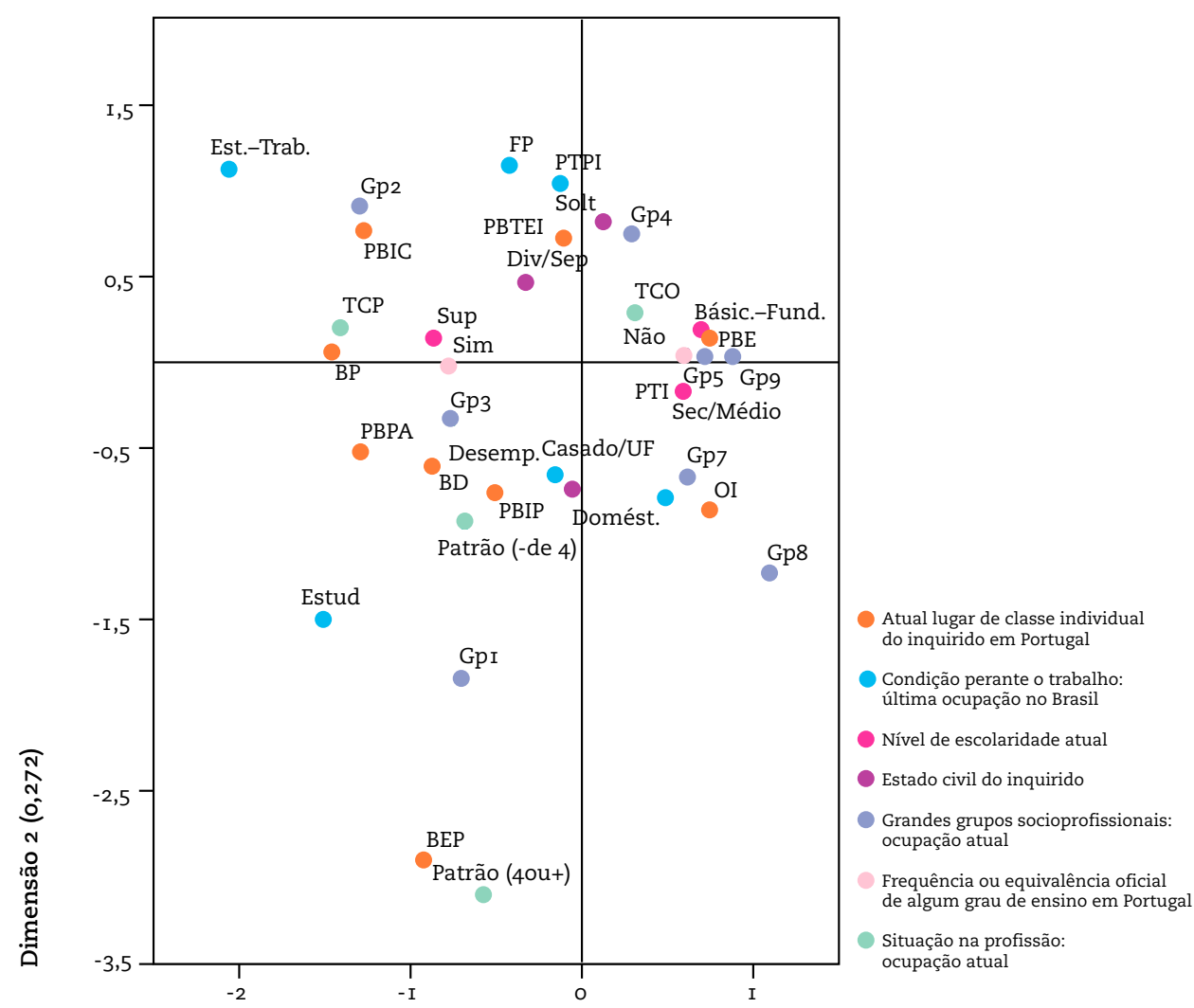

Dimensão I $(0,350)$

Gráfico 2:

Configuração topológica do espaço social da sociedade de acolhimento

Fonte:

Projeto coordenado pelo autor.

\section{Condição perante o trabalho:}

Profissão em tempo integral (PTI); Profissão em tempo parcial (PTP);

Estudante (Estud.); Estudante-trabalhador (Est.-Trab.); Doméstico (Domést.);

Desempregado (Desemp.); Formação profissional (FP).

Situação na profissão:

Patrão 4 ou + empregados (Patrão 4 ou +); Patrão - de 4 empregados

(Patrão - de 4); Trabalhador por conta própria (TCP); Assalariado/trabalhador

por conta de outrem (TCO).

Nível de escolaridade atual:

Ensino básico ou fundamental (Básic./Fund.); Ensino secundário ou médio

(Sec./Médio); Ensino superior (Sup.). Estado civil: Casado/união de fato

(Casado/UF); Divorciado/separado (Div./Sep.); Solteiro (Solt.).

Frequência ou equivalência oficial de algum grau de ensino em Portugal: Sim; Não.

As não respostas, porque residuais,

não foram incluídas na análise. 
Novamente, as variáveis gênero e idade permanecem como não discriminantes mesmo quando introduzimos as variáveis relativas à dimensão política da integração. No que diz respeito às variáveis retidas pela análise, a dimensão I se distingue pela variável escolaridade, enquanto a dimensão 2 é marcada pela associação das variáveis relacionadas à condição legal atual e ao tempo de permanência. Com relevância menor nesta última do que na dimensão I, as variáveis lugar de classe, grupos profissionais e situação legal na entrada protagonizam o que se chama de dupla pertença, ou seja, apresentam função discriminante em ambas as dimensões e vão descrever ambos os espaços.

Privilegiando as categorias que mais discriminam na primeira dimensão (alfa $=$ o,73I; variância explicada $=8,45 \%$ ), no lado esquerdo do plano se posicionam os indivíduos em frequência a nível superior de ensino ou que já o concluíram, os que trabalham nas profissões intelectuais e científicas (grupo 2), os que pertencem à BP e PBIC e que viajaram em condição legal mais estável, especificamente, com visto de estada temporária (VET) ou mesmo visto de residência (VR). Em oposição a esses, no lado direito do quadrante associam-se os indivíduos com nível de formação inferior (ensino básico/ fundamental e ensino secundário/médio), os trabalhadores dos serviços pessoais, de proteção e segurança e os vendedores (grupo 5), majoritariamente pertencentes à $\mathrm{PBE}$ e que arriscaram mais quando decidiram migrar, especificamente, ao abrigo da isenção de visto para fins turísticos.

Relativamente à dimensão 2 (alfa $=0,609$; variância explicada $=6,53 \%$ ), no quadrante inferior, associam-se os dirigentes, diretores e gestores executivos (grupo I), que pertencem à BEP e que do ponto de vista legal possuem (dupla) nacionalidade e se encontram há seis ou mais anos em Portugal. Por oposição, no quadrante superior, estão os profissionais das atividades intelectuais e científicas (grupo 2), que pertencem à PBIC e que são imigrantes em Portugal entre dois e cinco anos (média permanência), com posse de VET quando da entrada e atualmente.

Esses dados nos permitem concluir que a dimensão política não é indiferente à posição atual que o indivíduo ocupa na hierarquia de classes nem, intimamente relacionada a ela, à participação em grupos profissionais e aos recursos escolares do imigrante. Assim, além da relação que verificamos existir entre os recursos que o indivíduo foi capaz de mobilizar na sociedade de origem e seu processo de entrada em Portugal, observamos que os atuais recursos escolares, profissionais e de classe têm também relação com a situação legal na entrada em Portugal. Em bola de neve, os sujeitos que atualmente são menos capitalizados do ponto de vista escolar e socioprofissional são os que entraram em Portugal em situação mais frágil porque apenas habilitados à visita turística ao país. Pelo contrário, os que atualmente possuem elevado capital escolar, os que trabalham em áreas altamente qualificadas ou pertencem às classes sociais mais intelectualizadas entraram em 
Portugal com vistos correspondentes à intenção de permanecer no país para outros fins, sobretudo profissionais. Há, por isso, certa linha de continuidade nos percursos migrantes que liga as caraterísticas dos indivíduos na sociedade de origem, os meios legais que eles mobilizaram para migrar e suas caraterísticas atuais (Gráfico 3, p. 472).

Por fim, a dimensão 2 distingue os possuidores de capital escolar (PBIC) dos possuidores de capital econômico (BEP) e nos permite acrescentar que estes últimos são os que estão em Portugal há mais tempo e, do ponto de vista legal, os que mais se associam às situações de aquisição de (dupla) nacionalidade. Ou seja, acrescenta à informação anterior a de que tempo de permanência mais longo não é indiferente em relação à posição legal e de classe que esses imigrantes atingiram. No caso da PBIC, sua associação a tempo de permanência médio tem sobretudo a ver com o fato de, a partir de 2006, ter-se verificado enorme aumento dos que chegaram a Portugal para estudar, largamente associado à uniformização do sistema de ensino superior promovido pelo Processo de Bolonha.

\subsection{Configuração topológica da dimensão cultural}

Além das variáveis já abordadas, os processos de integração podem estar igualmente relacionados com o nível de contrastes e continuidades culturais e institucionais, e dependem, ainda, dos processos de integração social dos imigrantes, relacionados com a maior etnicização ou assimilação (Pires, $2003 a$ e 2003b) das redes de sociabilidade primárias e secundárias. Cabe lembrar que a etnicidade das relações sociais e a pertença a grupos associativos e religiosos fazem parte de todo um conjunto de variáveis que se podem distinguir, mas que têm boas chances de manter relações entre si (Merllié e Prévot, I997: 20).

\section{Configuração estrutural do espaço dos contrastes e continuidades culturais}

Mais uma vez, a análise invoca uma perspectiva multidimensional para uma compreensão mais completa do espaço das relações sociais (Gráfico 4), de modo que, juntamente com os indicadores relativos à percepção das diferenças culturais e do impacto que elas provocam, colocaram-se em observação variáveis de caraterização sociodemográfica, de participação nos grupos profis sionais, de localização de classe e de estatuto legal e tempo de permanência.

A análise suscitou duas constatações: existe efetivamente associação entre, de um lado, o capital escolar, a pertença a determinados grupos profissionais e frações de classe e, do outro, o reconhecimento e o nível de afetação relativamente aos diferentes domínios de cultura, embora menos evidente nos costumes e estilos de vida e crenças (dimensão I). A segunda constatação é a de que os diferentes domínios de cultura estão relacionados entre si ao nível do reconhecimento de sua existência e da afetação de suas consequências (dimensão 2). As variáveis demográficas gênero e idade, mais 


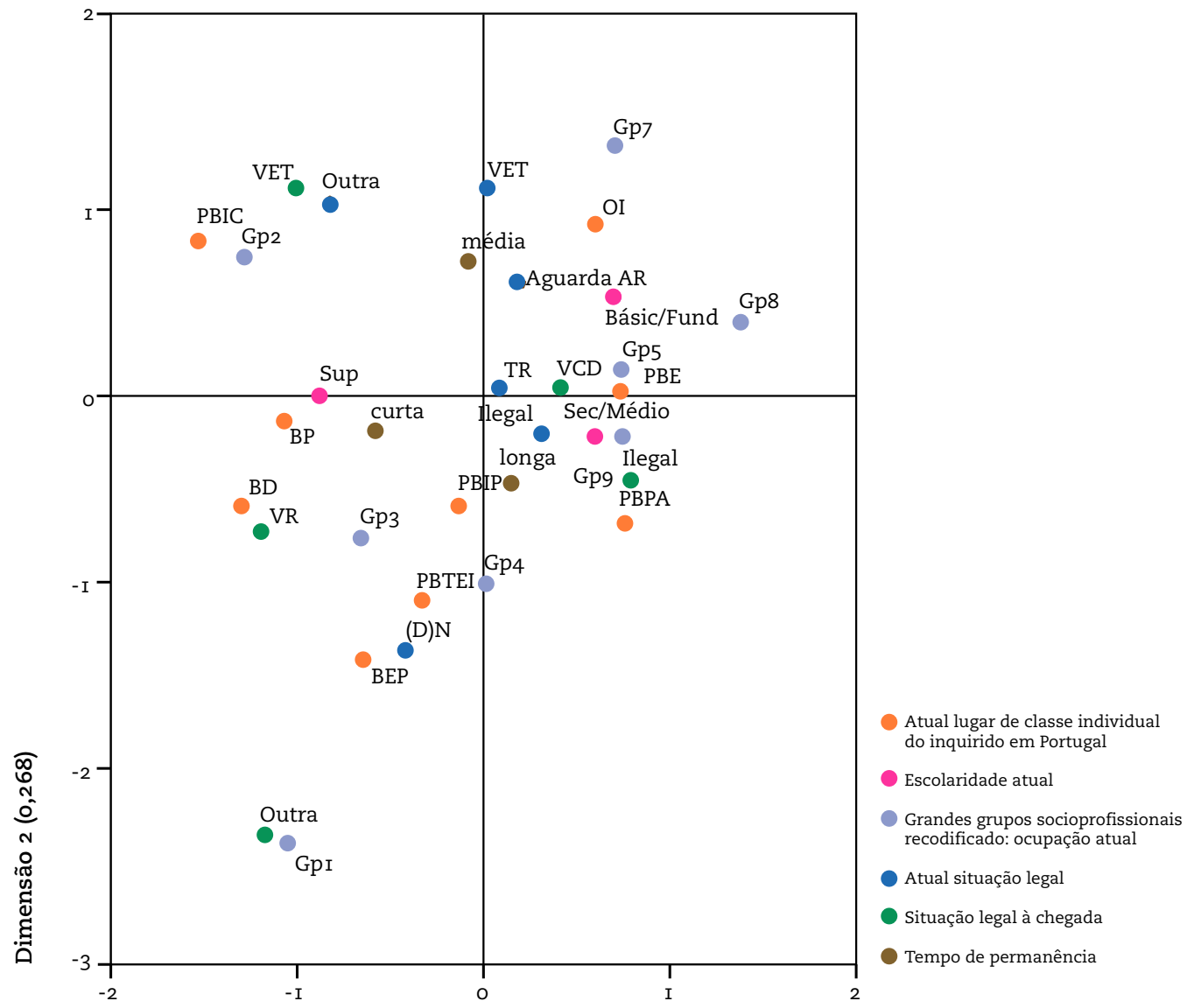

Dimensão I $(0,347)$

Gráfico 3:

Configuração topológica da dimensão política

Fonte:

Projeto coordenado pelo autor.

Situação legal na entrada:

Fins turísticos (FT); Visto de estada temporária (VET);

Visto de residência (VR); Ilegal; Outra.

Situação legal atual:

Visto de estada temporária (VET), Título de residência (TR);

Aguarda autorização de residência (Aguarda AR);

(Dupla nacionalidade (DN); Ilegal; Outra.

Tempo de permanência:

Curta permanência (Curta); Média permanência (Média);

Longa permanência (Longa).

Nível de escolaridade atual:

Ensino básico ou fundamental (Básic./Fund.); Ensino secundário ou médio (Sec./Médio); Ensino superior (Sup.). 
uma vez, não se revelaram discriminantes e, ao contrário do que se poderia esperar, também o tempo de permanência e o estatuto legal se revelaram indiferentes na discriminação desse espaço.

Nem todas as categorias das variáveis, porém, são necessariamente discriminantes. Assim, na dimensão I (alfa = 0,739; variância explicada = $7,39 \%$ ), no lado positivo do plano se encontram relacionados os sujeitos com frequência ou conclusão do nível secundário/médio de escolaridade, os trabalhadores dos serviços pessoais, de proteção e segurança e os vendedores (grupo 5), que pertencem à PBE e OI e que não reconhecem a existência de diferenças entre a sociedade brasileira e a portuguesa no nível da língua e dos valores, mas também (embora menos discriminante) no nível das crenças. Por oposição, no lado negativo do plano, associam-se os que completaram ou frequentam o ensino superior, os especialistas das atividades intelectuais e científicas (grupo 2), os que pertencem à PBIC ou BP e que não só consideram existir diferenças no nível dos valores, costumes e estilos de vida, como referem que essas diferenças têm impacto negativo em sua vida.

Verifica-se, portanto, que os recursos escolares, as pertenças profissionais e a posição de classe (altamente relacionados entre si) têm também estreita relação com o espaço das percepções e dos impactos dessas percepções em sua vida. Esses recursos que, por um lado, funcionam como instrumentos que podem ser utilizados de forma positiva para a integração, posto que capacitam seus portadores, podem, por outro lado, também funcionar como entraves a esse mesmo processo. Associado a um conhecimento crítico mais desperto, a integração desses imigrantes pode assim se tornar mais difícil devido à formação de certa resistência à aculturação.

Na segunda dimensão (alfa $=0,658$; variância explicada $=6,03 \%$ ), as variáveis relativas aos diferentes domínios culturais (costumes e estilos de vida, crenças, língua e valores) encontram-se inter-relacionadas. Particularmente, entretanto, o que a análise das categorias indica é que os indivíduos que consideram existir diferenças entre Portugal e Brasil em qualquer um dos domínios culturais, mas cujo efeito lhes é indiferente (plano inferior), opõem-se aos sujeitos que nesses mesmos domínios referem sentir-se positiva ou negativamente afetados por essas diferenças (plano superior). Ou seja, há um efeito bola de neve que faz com que, por exemplo, os indivíduos que em determinado domínio cultural tenham percepção positiva das diferenças, mas indiferenciada de seus impactos, revelem em outros domínios iguais percepção e afetação.

\section{Configuração estrutural do espaço dos contrastes e continuidades institucionais}

Com base no pressuposto de que a análise da confiança e satisfação política permite avaliar as condições em que os imigrantes estão ligados às instituições - questão central dos debates contemporâneos sobre integração dos 


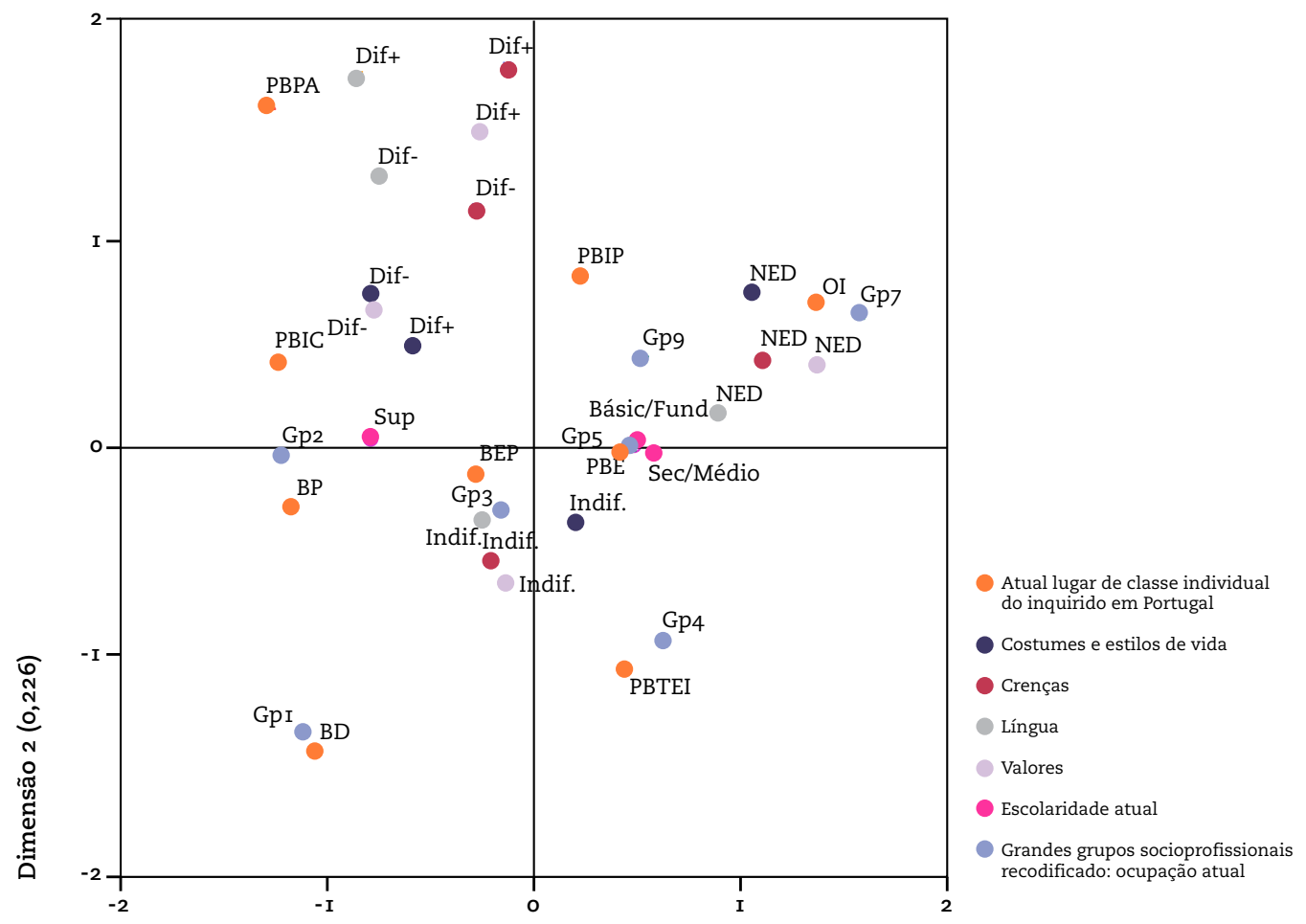

Dimensão I $(0,277)$

Gráfico 4:

Configuração estrutural do espaço dos contrastes

e continuidades culturais

Fonte:

Projeto coordenado pelo autor.

Diferenças culturais:

Não considero que existam diferenças (NED); Existem diferenças, mas me são indiferentes (Indf.); Existem diferenças que afetam minha vida positivamente (Dif.+); Existem diferenças que afetam minha vida negativamente (Dif.-).

Nível de escolaridade atual:

Ensino básico ou fundamental (Básic./Fund.); Ensino secundário ou médio (Sec./Médio); Ensino superior (Sup.). 
migrantes (Maxwell, 2010) -, introduzimos agora as opiniões quanto às instituições da sociedade portuguesa juntamente com as variáveis de caracterização sociodemográfica, de participação nos grupos profissionais, de localização de classe e de estatuto legal, bem como o tempo de permanência. Os resultados propõem novamente uma análise em duas dimensões (Gráfico 5). A primeira dominada pelo nível de confiança em face de todas as instituições da sociedade de acolhimento e dos recursos escolares, profissionais e de classe. A segunda é marcada pelo tempo de permanência e pela confiança no governo e na administração pública, nas associações de imigrantes e no Serviço de Estrangeiros e Fronteiras (SEF), embora o lugar de classe também discrimine nessa dimensão. Não são discriminantes as variáveis gênero e idade, mas também o estatuto legal atual do sujeito.

Na primeira dimensão (alfa $=0,757$; variância explicada $=6,04 \%$ ) associam-se, no lado esquerdo do plano, os indivíduos que do ponto de vista dos recursos frequentam algum nível do ensino superior ou já o completaram, especialistas intelectuais e científicos (grupo 2), e os que pertencem à PBIC e, do ponto de vista da confiança, têm posição neutra em relação ao governo e à administração pública, às associações, ao SEF e aos tribunais ou que confiam pouco nestes últimos e nos grupos religiosos. Opõem-se a esses, no lado direito do plano, os que possuem ensino secundário ou médio, os que trabalham no grupo do pessoal dos serviços e os vendedores (grupo 5), que pertencem à PBE e que, do ponto de vista da confiança depositada nas instituições, são mais radicais, isto é, ou "não confiam nada" no governo, nos tribunais, no SEF e nas associações de imigrantes ou "confiam muito" no SEF e nos grupos religiosos.

A segunda dimensão (alfa $=0,680$; variância explicada $=4,91 \%$ ), claramente marcada pelo tempo de permanência, mostra-nos, no lado negativo do plano, como se relacionam os sujeitos com permanência de curto prazo na sociedade de acolhimento (até um ano), que pertencem à fração de classe mais capitalizada escolarmente (PBIC) e que afirmam não ter opinião formada sobre o governo nem confiar nada no SEF. Opõem-se a esses os imigrantes com permanência em Portugal de longo prazo (seis anos ou mais), que pertencem à $\mathrm{PBE}$ e que, ao contrário dos anteriores, confiam no governo e sobre o SEF têm opinião neutra.

Em resumo, na linha do que vimos acontecer quanto às diferenças culturais, também no caso da confiança depositada nas instituições, o elevado nível de capital escolar e o exercício de profissão ligada à posse desse elevado capital escolar associam-se a opinião relativamente neutra sobre a atuação dessas instituições ou mesmo tendencialmente negativa nos casos dos tribunais e grupos religiosos. Já o capital escolar de nível secundário/ médio e o exercício de profissões mais ligadas à execução nos serviços - e, por isso, menos exigentes do ponto de vista do investimento escolar - associam-se particularmente a posições mais extremadas, em especial, de total 
ausência de confiança em todas as instituições em análise, com exceção dos grupos religiosos, que lhes suscitam total confiança.

No entanto, a complexidade da realidade social se revela quando percebemos que é também entre esses sujeitos que se posicionam as opiniões mais confiantes em relação ao SEF e às associações de imigrantes. É aí que entra outro vetor, o tempo de permanência, cujo poder explicativo nos foi dado pela dimensão 2. Com essa dimensão percebemos que longo tempo de permanência, quando associado à fração de classe da PBE (relacionada com o exercício de profissões executantes na área dos serviços), gera níveis de confiança mais elevados. Ou seja, se o capital escolar e a pertença a determinado grupo profissional explicam uma parte importante dos posicionamentos, essas variáveis não explicam tudo. Mais uma vez, a análise multidimensional se mostra assim fecunda e reveladora de dinâmicas que de outra forma não conseguiríamos compreender.

\section{Configuração estrutural do espaço da vivência do preconceito e/ou discriminação}

A par das políticas de imigração, para alguns autores, nada determina mais a forma como as sociedades veem os imigrantes e se posicionam em relação a eles do que as atitudes dos cidadãos. O preconceito é assim fator decisivo para uma integração bem-sucedida, podendo, aliás, a não aceitação da sociedade de acolhimento bloquear as políticas de integração (Arango, I999: 242; Fonseca, 2004: III). Em nossa pesquisa quisemos também avaliar a existência desse tipo de comportamentos e sua relação com as variáveis da dimensão social e política (Gráfico 6, p.479).

Novamente, em seu contexto multidimensional, o gênero não se revelou variável significativa para a descrição desse espaço social, bem como as variáveis relativas à dimensão política e à discriminação por razões profissionais e raciais, mas outras relações são bastante interessantes. A dimensão I é notadamente marcada pela associação dos recursos escolares, profissionais e de classe e pelas variáveis relativas à experiência do preconceito e/ou discriminação e respectivas razões étnicas e de gênero. Já a dimensão 2 se define pela associação das variáveis ligadas ao posicionamento de classe, pertença profissional, idade e discriminação de gênero.

Focalizemos as categorias que de fato discriminam na dimensão I (alfa $=0,7$ I 3 ; variância explicada $=8,62 \%$ ). No lado direito do plano, associam-se os indivíduos com ensino secundário/médio, os trabalhadores dos serviços pessoais, de proteção e segurança, e os vendedores (grupo 5) e os que pertencem à $\mathrm{PBE}$ e que em nenhum momento se sentiram vítimas de preconceito e/ou discriminação de qualquer natureza. 


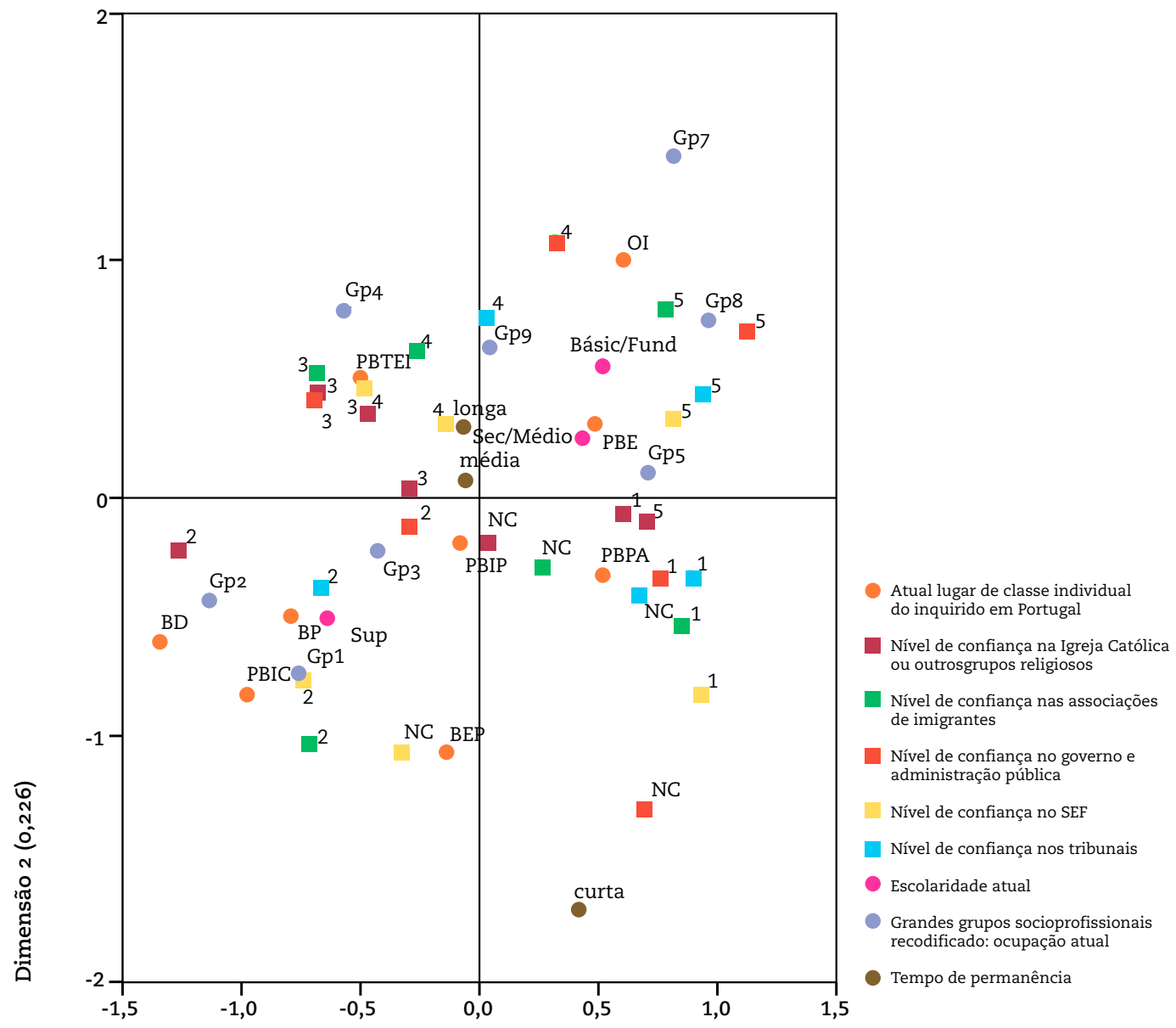

Dimensão 1 (0,272)

Gráfico 5:

Configuração estrutural do espaço dos contrastes e continuidades institucionais

Fonte:

Projeto coordenado pelo autor.

Nível de confiança nas instituições:

Não confio nada (I); Não confio (2); Não confio nem desconfio (3); Confio (4); Confio muito (5); Não conheço (NC).

Nível de escolaridade atual:

Ensino básico ou fundamental (Básic./Fund.); Ensino secundário ou médio (Sec./Médio); Ensino superior (Sup.). 
No outro lado do plano estão relacionados os sujeitos que frequentam ou já concluíram o ensino superior, os especialistas das atividades intelectuais e científicas (grupo 2), os que pertencem à BP e à PBIC e que não só afirmam ter sido vítimas de preconceito e discriminação, como acrescentam que a discriminação tem razão étnica e/ou de gênero. Levanta-se aqui uma questão que, do nosso ponto de vista, poderá ter duas interpretações não excludentes. Por um lado, o fato de os sujeitos mais escolarizados, os que trabalham em áreas mais exigentes do ponto de vista das qualificações e que têm pertenças a frações de classe bem posicionadas na hierarquia de classes conviverem em círculos sociais mais competitivos e nos quais os fatores eliminatórios são mais exigentes. Por outro, o fato de eles possuírem maior sensibilidade crítica ou estarem mais despertos para essa realidade.

Inversamente, os sujeitos um pouco menos escolarizados, que trabalham em áreas profissionais menos exigentes do ponto de vista das qualificações e que pertencem a frações de classe menos bem posicionadas conviverão em núcleos sociais menos competitivos, nos quais geralmente existe até um "mercado" para os brasileiros não diretamente concorrencial com os portugueses. Se existe concorrência, é, sem dúvida, entre brasileiros naquilo que Renó Machado (2009: 78-87) chama de jogo da centralidade com base na representação da "identidade-para-o-mercado", isto é, na ideia de que existem algumas caraterísticas definidoras da essência do brasileiro (alegria, malemolência, bondade, camaradagem e hipersexualidade) e que são essenciais na conquista de um dos postos de trabalho para brasileiros em Portugal.

Com relação à dimensão 2, ela acrescenta outro dado (alfa $=0,566$; variância explicada =6,19\%). No lado positivo do plano, a análise das categorias que mais diferenciam nos permite, ainda, relacionar a idade e o lugar de classe com a discriminação de gênero ou, em outras palavras, os sujeitos entre 30 e 39 anos de idade, que pertencem ao OI e que afirmam se sentir vítimas de preconceito e/ou discriminação por razões de gênero. ${ }^{8}$ Apesar de a variável gênero não ser discriminante, mas sabendo que a quase totalidade dos imigrantes que assumiram essa vivência é de mulheres, podemos afirmar que mesmo entre frações de classe na base da hierarquia de classes, como é o caso do OI, ser mulher brasileira e ter entre 30 e 39 anos de idade são também caraterísticas que se relacionam com a experiência do preconceito e/ou discriminação de gênero.

\section{Configuração estrutural do espaço das redes de sociabilidade e da pertença a grupos}

Por fim, adicionamos à análise as questões da maior ou menor etnicização ou assimilação das relações sociais nos núcleos de sociabilidade primários (familiares, de amizade, trabalho e vizinhança) e secundários. Posto isso, às variáveis relativas às dimensões social e política juntaram-se as variáveis 


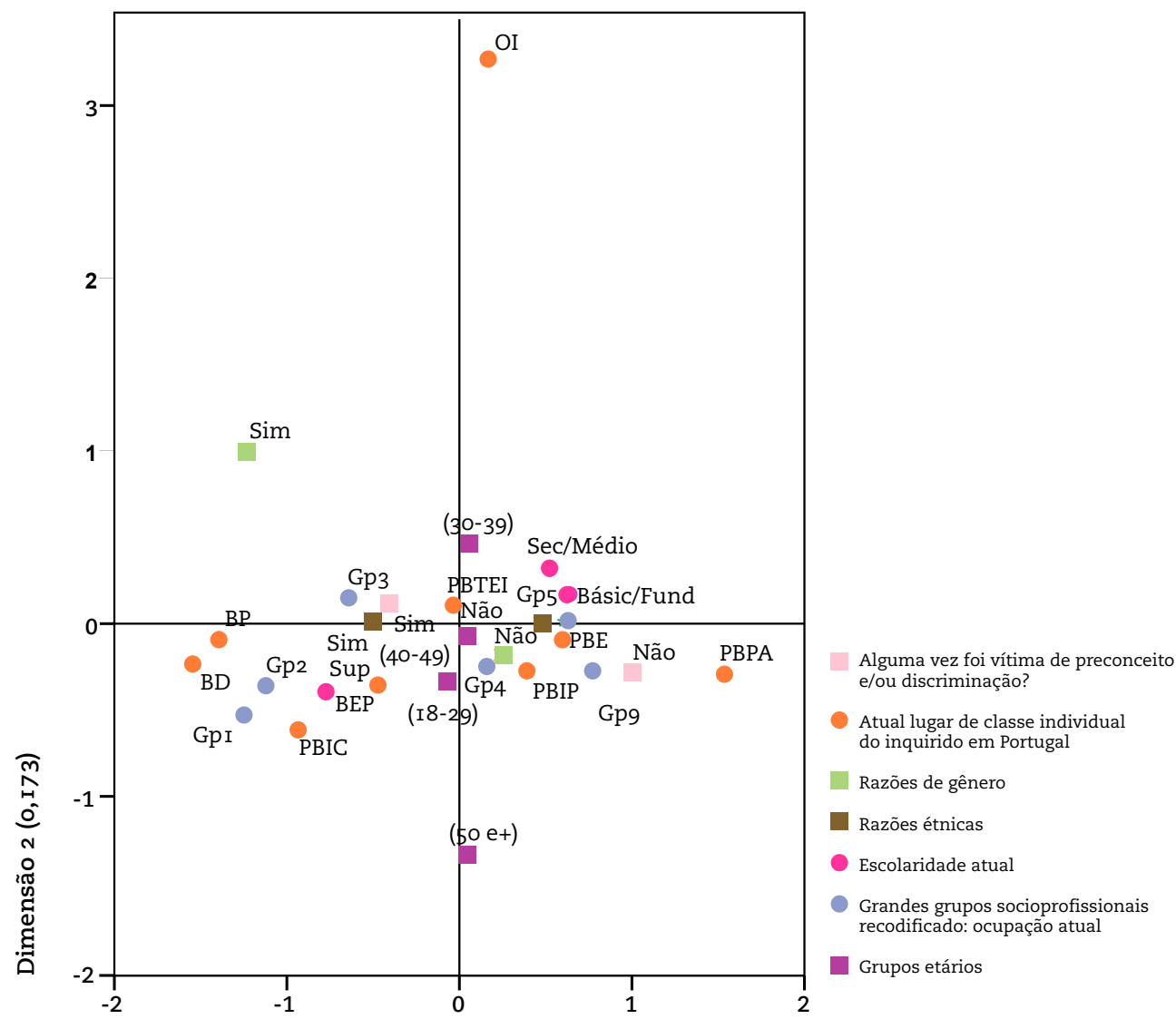

Dimensão $1(0,24 \mathrm{I})$

Gráfico 6:

Configuração estrutural do espaço da vivência do preconceito

e/ou discriminação e suas razões

Fonte:

Projeto coordenado pelo autor.

Vítima de preconceito e/ou discriminação: Sim; Não.

Por razões de gênero: Sim; Não.

Por razões étnicas: Sim; Não.

Nível de escolaridade atual:

Ensino básico ou fundamental (Básic./Fund.); Ensino secundário ou médio (Sec./Médio); Ensino superior (Sup.).

Grupos etários: $18-29$ anos (18-29); 30-38 anos (30-39);

40-49 anos (40-49); 50 e mais anos de idade $(50 \mathrm{e}+$ ). 
sobre a composição das redes de sociabilidade primárias e a pertença a redes de sociabilidade secundárias (Gráfico 7, p. 48I).

Como tem sido habitual, a idade não se mostra variável discriminante, tampouco o tempo de permanência. Outras variáveis descrevem melhor esse espaço. Especificamente, com uma situação de dupla pertença, o lugar de classe e a pertença profissional discriminam em ambas as dimensões, destacando-se a dimensão I, ainda por relacionar o nível de escolaridade e a situação legal atual com a composição étnica das redes de amizade e vizinhança. Já a dimensão 2 se diferencia pelo gênero e, novamente, pela composição das redes de amizade, mas também as familiares e de trabalho. Vejamos agora como isso se concretiza em termos de categorias efetivamente discriminantes.

O que a dimensão I (alfa $=0,685$; variância explicada $=6,24 \%$ ) nos revela é como, no lado esquerdo do plano, estão associados os sujeitos com (dupla) nacionalidade, os que possuem nível de escolaridade superior, os que trabalham nos grupos profissionais mais especializados (grupos I, 2) e que pertencem às correspondentes frações de classe - com ou sem controle sobre os meios de produção (BD, PBIC e BP) - e cujos amigos e vizinhos com quem mais se relacionam são sobretudo portugueses. Por oposição, no lado direito, associam-se os imigrantes que possuem o ensino básico/fundamental e secundário/médio, os que trabalham em áreas pouco exigentes do ponto de vista das qualificações e competências (grupos 5 e 9), os que pertencem à PBE e cujos amigos e vizinhos são majoritariamente brasileiros.

Na dimensão 2 (alfa = 0,63I; variância explicada = 5,48\%), no flanco positivo se associam os homens, os especialistas das atividades intelectuais e científicas (grupo 2), os que pertencem à PBIC, os que têm amigos majoritariamente brasileiros e os que não têm família residindo em Portugal. Do lado oposto, estão relacionados os imigrantes do gênero feminino, os trabalhadores qualificados da indústria, construção e artífices (grupo 7), que pertencem ao OI e os que têm sobretudo familiares de origem portuguesa ou que não têm relações no trabalho.

Se por um lado, portanto, o trabalho em áreas mais exigentes do ponto de vista das qualificações ou a pertença a frações de classe mais bem posicionadas na hierarquia de classes estão associados a maior interetnicidade das relações sociais de amizade e vizinhança, sobretudo quando a isso se acresce a posse de (dupla) nacionalidade, por outro lado, esse mesmo exercício de alguma atividade exigente do ponto de vista intelectual também se associa a relações mais etnicizadas no grupo de amigos e de trabalho quando a isso se acrescenta o fato de serem homens e não terem família residindo em Portugal. 


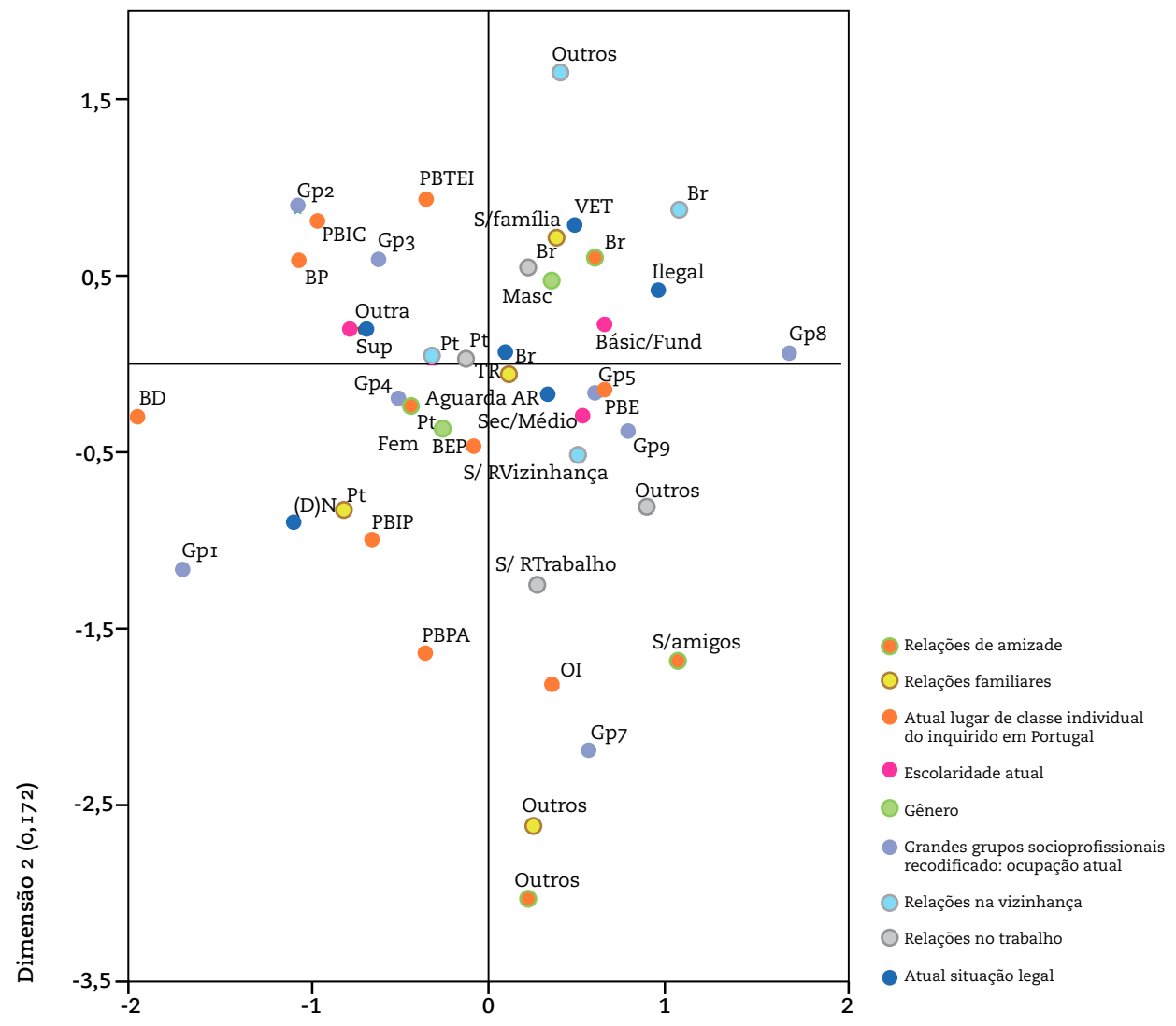

Dimensão 1 (0,196)

Gráfico 7:

Configuração estrutural do espaço das redes de sociabilidade

e da pertença a grupos

Fonte:

Projeto coordenado pelo autor.

A maioria de meus familiares vivendo em Portugal é...: portuguesa $(\mathrm{Pt})$; brasileira $(\mathrm{Br})$; de outra origem (outra); não tem familiares (S/família).

A maioria de meus amigos em Portugal é...:

portuguesa (Pt); brasileira (Br); de outra origem (outros); não tem amigos (S/amigos).

No trabalho relaciono-me sobretudo com...:

portugueses $(\mathrm{Pt})$; brasileiros (Br); de outra origem (outros); não tem relações de trabalho (S/RTrabalho).

$\mathrm{Na}$ vizinhança relaciono-me sobretudo com...:

portugueses (Pt); brasileiros (Br); de outra origem (outros); não tem relações de vizinhança (S/RVizinhança).

Situação legal atual:

Visto de estada temporária (VET), Título de residência (TR);

Aguarda autorização de residência (Aguarda AR);

Dupla nacionalidade (DN); Ilegal; Outra.

Nível de escolaridade atual:

Ensino básico ou fundamental (Básic./Fund.); Ensino secundário ou médio (Sec./Médio); Ensino superior (Sup.).

Grupos etários:18-29 anos (18-29); 30-38 anos (30-39);

40-49 anos (40-49); 50 e mais anos de idade (50 e +). 
Pelo contrário, se o exercício de uma profissão menos qualificada no setor dos serviços - associada a nível de escolaridade não superior e a pertença inferior na hierarquia de classes -, por um lado, associa-se a maior fechamento étnico ou mesmo a isolamento com relação à vizinhança; por outro lado, no caso de o exercício dessa profissão menos qualificada se realizar no setor industrial ou de se tratar de uma mulher, as relações familiares tendem a ser predominantemente interétnicas, e os laços de amizade e trabalho, inexistentes. Em resumo, como já tinha acontecido antes, se as pertenças profissional e classista explicam também a configuração do espaço das relações sociais, essas pertenças não explicam tudo. Neste caso em particular, é muito evidente que a estruturação das relações sociais primárias está também associada ao gênero, ao setor de trabalho, à escolaridade ou, ainda, à posse de um estatuto legal que identifica o sujeito não mais como imigrante, mas como cidadão português em igualdade total de circunstâncias perante a lei relativamente aos nacionais do país de acolhimento.

Já no que diz respeito à pertença a grupos de natureza associativa, religiosa ou outra, resta acrescentar que a ausência de relações específicas entre estas e as variáveis sociais e políticas não é sinônimo de que a pertença a esses grupos não seja significante. O que acontece é que essa pertença não se revelou significativamente associada a nenhuma das caraterísticas em análise, podendo indicar que a pertença a estes grupos é transversal ao gênero, às idades, às classes sociais, aos diferentes níveis de escolaridade, à condição legal e ao tempo de permanência.

Em conjunto, os dados nos permitem distinguir dois perfis. Primeiro, um fluxo de imigrantes profissionalmente ativos, com formação superior e no exercício de profissões qualificadas que, mesmo em plena "segunda vaga"/ onda, e particularmente a partir de 2006, continuam chegando a Portugal. Imigrantes que viajaram em condição legal estável, especificamente, com visto de estada temporária (VET) ou mesmo visto de residência (VR). Indivíduos estruturalmente bem integrados, mas não isentos de contradições em outros níveis: certa resistência à aculturação; indiferença quanto à atuação das instituições e crítica à atuação dos tribunais e grupos religiosos; são os que mais afirmam ter sido vítima de preconceito e/ou discriminação; e os que apresentam maior interetnicidade nas relações sociais de amizade e vizinhança apresenta.

Um segundo perfil diz respeito a um fluxo de imigrantes também profissionalmente ativos, com nível básico ou secundário de escolaridade, particularmente ligados ao grupo dos serviços e aos vendedores e que a partir da viragem do século engrossa a camada populacional de brasileiros em Portugal. Por outro lado, são imigrantes que arriscaram mais quando decidiram migrar, uma vez que estavam ao abrigo da isenção de visto para fins turísticos; e são indivíduos com uma integração estrutural mais frágil, mas também 
com algumas particularidades: ausência geral de confiança nas instituições, com exceção dos grupos religiosos que lhes suscitam total confiança; são os que menos afirmam ter sido vítimas de preconceito e/ou discriminação; e os que apresentam maior intraetnicidade das relações sociais de amizade e vizinhança.

\section{CONSIDERAÇÕES FINAIS}

Sem pretensão de extrapolação, os resultados desta pesquisa ajudam a levantar pistas sobre possíveis especificidades dos imigrantes brasileiros residentes no Grande Porto. Particularmente, sobre a persistência de um fluxo de imigrantes brasileiros profissionalmente ativos, com formação superior e no exercício de profissões qualificadas que mesmo em plena segunda onda continuam chegando a Portugal. Uma franja da população que tendemos a subvalorizar quando pensamos na imensa onda de imigrantes que a partir de meados de 1990 entrou em Portugal. Isso se deve, entre outras possíveis razões, como nos lembra Vermeulen (200I: I3), ao fato de a ciência e a política se direcionarem sobretudo para os grupos problemáticos, esquecendo os grupos bem-sucedidos ou integrados de forma imperceptível na sociedade circundante. Pelo menos, estruturalmente bem integrados - isto é, integrados na sociedade de acolhimento numa das dimensões mais relevantes da vida dos sujeitos, marcada, especialmente, pelo emprego -, até porque estes sujeitos revelaram um processo de integração não isento de contradições em outros níveis.

Os recursos escolares, a pertença profissional e classista, além de altamente relacionados entre si, são as variáveis que, verificamos, mais descrevem as diferentes dimensões em análise. Desde logo, marcam a configuração do espaço social da sociedade de origem, tendo-nos permitido aferir a existência de perfis diferentes. Indivíduos que, além de se distinguir pelo ciclo de vida em que se encontravam quando decidiram emigrar, distinguem-se pelos níveis de sua qualificação escolar e profissional, e que, em razão dessas duas condições, buscam objetivos diferentes com o projeto migratório. Por seu lado, é também a forma como estão associados os diferentes níveis de escolaridade, os grupos profissionais e os lugares de classe que nos ajudam a perceber como está organizado o espaço social da sociedade de acolhimento, tendo-nos permitido concluir que, tal como na sociedade de origem, existe um conjunto de caraterísticas que organizam e distinguem os sujeitos. Além disso, num contexto em que esses imigrantes gozam politicamente de posição privilegiada em relação a outros grupos de imigrantes, percebemos como, a par da origem étnica, as caraterísticas sociais se relacionam com o processo legal de entrada em Portugal e, ainda que parcialmente, com o estatuto legal atual. Por fim, concluímos como o lugar de classe (e as variáveis que estão associadas) nos ajuda a descrever os contrastes e continui- 
dades culturais e institucionais, a vivência do preconceito e/ou discriminação e a maior ou menor etnicização das redes de sociabilidade.

Ainda, a análise multivariada nos permitiu perceber que, apesar de sua centralidade, as variáveis capital escolar, grupo profissional e lugar de classe não explicam tudo. Nesse sentido, observamos como algumas categorias da situação legal dos imigrantes e do tempo de permanência se associam a determinados níveis de confiança depositados nas instituições e à etnicidade das redes de sociabilidade. Ou, no caso das variáveis sociodemográficas, como o gênero e a idade ajudam analogamente a explicar a vivência do preconceito e/ou discriminação e, ainda, determinadas redes de sociabilidades.

No conjunto, porém, as variáveis associadas à posição de classe exerceram sempre um poder descritivo, o que nos leva a corroborar a hipótese de que os processos de integração na sociedade de acolhimento não são indiferentes ao lugar de classe que o imigrante ocupa. Uma posição que se relaciona com seus pontos de partida (Sayad, I999), isto é, que começa desde a emigração, na sociedade de origem. Em particular, observamos como, entre esses imigrantes, os trajetos de mobilidade social na sociedade de acolhimento têm relação direta com os lugares de classe ocupados na sociedade de origem, permanecendo grande parte dos imigrantes em situação de continuidade em relação a essa localização, o que é bem mais evidente entre os provenientes das classes mais providas de capital escolar, bem como nas mais desprovidas de capital econômico e escolar. As descontinuidades se devem sobretudo a movimentações entre frações de classe - protagonizando, por isso, situações que dizem respeito a trajetos de descontinuidade fracos - e particularmente no sentido de intensificação das classes que mais se relacionam com a tendência de terceirização da economia.

Em resumo, observamos forte relação entre as diferentes dimensões em análise, mas em particular forte influência da dimensão social nos processos de integração, designadamente das variáveis que estão intimamente relacionadas com a definição do lugar de classe. Por seu lado, a dimensão política teve seus efeitos minimizados sobretudo pela centralidade que a dimensão social assumiu, não esquecendo que as duas se apresentaram largamente relacionadas. Por último, mais do que explicar os processos de integração, a dimensão cultural nos ajudou a perceber o efeito bola de neve que algumas categorias das variáveis sociais, mas também políticas, assumem na compreensão da forma como o espaço cultural está organizado, podendo acentuar ou minimizar contrastes culturais e institucionais e reforçar ou atenuar os efeitos de etnicização das sociabilidades.

Por essas razões, o Grande Porto se apresenta como espaço fragmentado por categorias de indivíduos socialmente diferenciados e no qual as múltiplas possibilidades de interação que a lógica urbana potencializa resultam, na verdade, em aproximações para uns e distanciamentos para outros. A moderni- 
dade e o desenvolvimento das democracias, tantas vezes associados a um sistema político que garante e promove a igualdade nas sociedades ocidentais, não conseguem evitar uma ordem econômica dominante que está na origem de uma das principais contradições ou falhas da modernidade, a crise "igualdade-desigualdade" (Fenton, 2004). Uma crise com consequências, entre outros aspectos, na fixação legal dos imigrantes e no reforço dos contrastes étnicos, institucionais, culturais e religiosos. Por muito que as políticas migratórias e de integração estejam direcionadas para a acomodação da diversidade, no nível da vida real a mistura social e cultural tende a resistir.

Recebido em I7/02/2017 | Aprovado em I5/06/2017

Maria João Oliveira é doutora em sociologia pela Universidade do Porto, colaboradora no Instituto de Sociologia da mesma instituição e pesquisadora no Research in Education and Community Intervention (RECI). Tem desenvolvido pesquisas na área das migrações, religiões e, mais recentemente, na área da cooperação para o desenvolvimento. Autora de "Espaços de religiosidade no Porto: o seu papel na integração dos imigrantes brasileiros" (2012) e coautora, com Helena Vilaça, de "Portrait du catholicisme au Portugal" (20I2) e "Ethical challenges of the Catholic Church in Portugal: the case of same-sex-Marriage" (20I5). 


\section{NOTAS}

I O Grande Porto é uma área geográfica definida com base na nomenclatura das unidades territoriais estatísticas de nível 3 (Nuts III) (decreto-lei n. 68/2008).

2 Devido à dimensão do trabalho, não serão apresentados aqui os resultados da metodologia intensiva.

3 Aplicou-se o questionário em ginásios, centros comerciais e restaurantes, na rua e na associação de imigrantes brasileiros Mais Brasil, e, finalmente, por indicação de pessoas conhecidas.

4 No total, entre janeiro e setembro de 20I I, foram coletados I46 inquéritos válidos.

5 A matriz aqui apresentada baseia-se na atualização que Magalhães (2005; 1994) faz da original Matriz de Construção dos Lugares de Classe dos Indivíduos, elaborada por Almeida, Costa e Machado (I988) e atualizada em Costa, Machado e Almeida (I990).

6 As freguesias correspondem às subprefeituras brasileiras, mas são governadas por um órgão executivo escolhido nas eleições para a Assembleia de Freguesia.

7 Critério quantitativo: o valor médio de referência para considerar ou não relevantes as contribuições das categorias nas dimensões em análise = I/n. de categorias.

8 A importância da variável "grupos profissionais" na dimensão 2 deve-se a categorias que são outliers e, por conseguinte, não foi considerada na análise.

\section{REFERÊNCIAS BIBLIOGRÁFICAS}

Almeida, João Ferreira de. (I993). Integração social e exclusão social: algumas questões. Análise Social, XXVIII/I23-I24, p. 829-834.

Almeida, João Ferreira de; Costa, António Firmino da \& Machado, Fernando Luís. (1988). Famílias, estudantes e universidade - painéis de observação sociográfica. Lisboa: CiesIscte/Celta.

Alves, Jorge. (I994). Os brasileiros: emigração e retorno no Porto oitocentista. Porto: Gráficos Reunidos. 
Arango, Joaquín. (I999). Immigrants in Europe: between integration and exclusion. In: Vicente, Paula (coord.). Metropolis international workshop, Proceedings. Lisboa: Fundação Luso-Americana para o Desenvolvimento, p. 23I-256. Bógus, Lúcia. (2007). Esperança além-mar: Portugal no "arquipélago migratório" brasileiro. In: Malheiros, Jorge (org.). Imigração brasileira em Portugal. Lisboa: Acidi, p. 39-58.

Bourdieu, Pierre. (2010) [1979]. A distinção: uma crítica social da faculdade do juízo. Lisboa: Edições 70.

Bourdieu, Pierre. (I980). Le capital social: notes provisoires. Actes de la Recherche en Sciences Sociales, 3I/I, p. 2-3. Castles, Stephen; Miller, Mark. (2003). The age of migration: international population movements in the modern world. New York: Palgrave Macmillan.

Costa, Firmino da. (I999). Sociedade de bairro: dinâmicas sociais da identidade. Oeiras: Celta.

Costa, António Firmino da; Machado, Fernando Luís \& Almeida, João Ferreira de. (I990). Estudantes e amigos: trajetórias de classe e redes de sociabilidade. Lisboa: Imprensa de Ciências Sociais.

Creswell, John. (1994). Research design: qualitative \& quantitative approaches. California: Sage.

Eurostat, Statistics database. (2014). Disponível em <http://epp.eurostat.ec.europa.eu>. Acesso em 30 jul. 2017. Fenton, Steve. (2004). Modernidade, etnicidade e religião. In: Rodrigues, Donizete (org.). Em nome de Deus: a religião na sociedade contemporânea. Porto: Afrontamento, p. 5I-75. Ferreira, Virgínia. (2003). O inquérito por questionário. In: Silva, Augusto Santos \& Pinto, José Madureira (orgs.). Metodologia das ciências sociais. Porto: Afrontamento, p. I65-196.

Fonseca, Maria Lucinda. (2004). Dinâmicas de integração dos imigrantes: estratégias e protagonistas. In: Alto Comissariado para a Imigração e Minorias Étnicas (org.). Actas do I Congresso Imigração em Portugal: diversidade-cidadania-integração. Lisboa: Acime, p. I08-I40.

Góis, Pedro \& Marques, José Carlos. (2009). Portugal as a semi-peripheral country in the global migration system. International Migration Review, 47/3, p. 2I-50. 
Heckmann, Friedrich. (2005). National modes of immigrant integration. In: Bosswick, Wolfgang \& Husband, Charles (orgs.). Comparative european research migration, diversity and identities. Bilbao: University of Deusto, p. 99-I I I. Kritz, Mary; Lim, Lin Lean \& Zlotnik, Hania. (1992). International migration systems: a global approach. Oxford: Clarendon Press.

Mabogunje, Akin L. (I970). Systems approach to a theory of rural-urban migration. Geographical Analysis, 2/I, p. I-I7. Machado, Fernando Luís. (2002). Contrastes e continuidades: migração, etnicidade e integração dos guineenses em Portugal. Oeiras: Celta.

Machado, Fernando Luís \& Abranches, Maria. (2007). O capital social externo dos imigrantes. In: Vala, Jorge \& Torres, Anália (orgs.). Contextos e atitudes sociais na Europa: atitudes sociais dos portugueses. Lisboa: Imprensa de Ciências Sociais, p. 25I-269.

Magalhães, Dulce Maria. (2005). Dimensão simbólica de uma prática social: consumo do vinho em quotidianos portuenses. Tese de Doutorado. Faculdade de Letras da Universidade do Porto.

Magalhães, Dulce Maria. (I994). Classes sociais e trajectórias intergeracionais. Sociologia, Revista da Faculdade de Letras da UP, 4, p. I73-217.

Malheiros, Jorge. (2007). Os brasileiros em Portugal: a síntese do que sabemos. In: Imigração brasileira em Portugal. Lisboa: Acidi, p. II-37.

Maxwell, Rahsaan. (2010). Evaluating migrant integration: political attitudes across generations in Europe. International Migration Review, 44/I, p. 25-52.

Merllié, Dominique \& Prévot, Jean. (I997). La mobilité sociale. Paris: La Découverte.

Nunes, Sedas \& Miranda, David. (I969). A composição social da população portuguesa: alguns aspectos e implicações. Análise Social, VII/27-28, p. 333-38I.

Pires, Rui Pena. (2003a). Migrações e integração: teoria e aplicações à sociedade portuguesa. Oeiras: Celta. 
Pires, Rui Pena. (2003b). Processos de integração na imigração. In: Cordeiro, Graça Índias et al. (orgs.). Etnografias urbanas. Oeiras: Celta, p. 63-76.

Portes, Alejandro. (2000). Capital social: origens e aplicações na sociologia contemporânea. Sociologia, Problemas e Práticas, 33, p. I33-I58.

Renó Machado, Igor. (2009). Cárcere público: processos de exotização entre brasileiros no Porto. Lisboa: Imprensa de Ciências Sociais.

Sayad, Abdelmalek. (1999). La double absence: des illusions de l'émigré aux souffrances de l'immigré. Paris: Seuil.

Vilaça, Helena. (2008). Imigração, etnicidades e religião: o papel das comunidades religiosas na integração dos imigrantes da Europa de Leste. Lisboa: Acidi/OI.

Vala, Jorge. (I996). Identidades, estruturas cognitivas e transformações culturais. In: Actas das sessões plenárias do III Congresso Luso-Afro-Brasileiro: Dinâmicas multiculturais, novas faces, novos olhares. Lisboa: Imprensa de Ciências Sociais, p. 25-29.

Vermeulen, Hans. (200I). Imigração, integração e a dimensão política da cultura. Lisboa: Edições Colibri.

Weber, Max. (1983). A ética protestante e o espírito do capitalismo. Lisboa: Presença. 


\section{INSCRIÇÕES NO ESPAÇO SOCIAL: OS IMIGRANTES BRASILEIROS NO GRANDE PORTO}

Resumo

Este artigo pretende contribuir para o aprofundamento da compreensão dos processos de integração dos imigrantes nas sociedades de acolhimento. Debruçamo-nos sobre os imigrantes brasileiros no Grande Porto com o objetivo de compreender como as migrações - por meio da análise das dimensões social, política e cultural do fenômeno - se relacionam com as inscrições desses imigrantes no espaço social. Enquadrados pela teoria dos sistemas migratórios e com recurso ao inquérito por questionário, os resultados da pesquisa validam a existência de forte relação entre as diferentes dimensões em análise e destacam a influência que a dimensão social assume nos processos de integração. A dimensão cultural ajudou-nos a perceber o efeito bola de neve que algumas categorias das variáveis sociais e políticas assumem na compreensão da forma como o espaço cultural está organizado.

\section{INSCRIPTIONS IN SOCIAL SPACE: BRAZILIAN IMMIGRANTS IN GREATER OPORTO}
Abstract
This article aims to contribute to the understanding of the process of integration of immigrants in host-societies. We studied Brazilian immigrants in Oporto in order to under- stand, through the analysis of the phenomenon's social, political and cultural dimensions, how migrations are as- sociated with the inscriptions of these immigrants in the social space. By taking into account migration systems theory and by resorting to a survey, the research's results validate the existence of a strong relation between the dif- ferent dimensions analysed and also stress the influence of the social dimension in the integration processes. The cultural dimension was useful in understanding the snow- ball effect that some social and political variables assume in the comprehension of how cultural space is organised.

Palavras-chave

Imigração;

integração;

brasileiros;

Porto (Portugal);

teoria dos sistemas

migratórios.

\section{Keywords}

Immigration;

integration;

Brazilians;

Oporto (Portugal);

migration systems

theory. 